Faculty of Special Education and Rehabilitation,

University of Belgrade

Nenad P. Glumbić

Faculty of Special Education and Rehabilitation, University of Belgrade

\title{
A COMPARISON OF INDIVIDUAL QUALITIES OF RESILIENCY IN ADOLESCENTS WITH MILD INTELLECTUAL DISABILITY AND TYPICALLY DEVELOPING ADOLESCENTS²
}

\begin{abstract}
Intellectual disability (ID) is a chronic adversity that increases the likelihood of negative developmental outcomes. The aim of this research is to examine differences between adolescents with mild ID and typically developing (TD) adolescents in personal qualities which contribute to successful adaptation. The sample consisted of 92 adolescents with mild ID and 772 TD adolescents, 13-19 years of age, of both sexes. Resiliency was assessed using the Resiliency Scales for Children and Adolescents. In comparison to TD adolescents, adolescents with mild ID have significantly lower levels of sense of mastery and sense of relatedness and a higher level of emotional reactivity. In the subsample of adolescents with mild ID there were no age or sex differences for resiliency. Adolescents with mild ID have a lower level of resiliency than TD adolescents, which highlights the need to develop programs focused on personal qualities associated with positive developmental outcomes.
\end{abstract}

Keywords: adolescent, intellectual disability, resiliency

\section{Introduction}

Various definitions of resilience can be found in the literature. However, most contemporary authors describe resilience as positive adaptation despite significant adversity (Luthar et al., 2015; Sameroff \& Rosenblum, 2006). In the context of thus defined resilience, intellectual disability (ID) can be observed as chronic adversity that impedes psychosocial functioning or a high-risk condition that increases the likelihood of negative development

$1 \quad$ E-mail: miroslavpavlovic@zuov.gov.rs

2 This paper is a result of the project Social Participation of Persons with Intellectual Disability(No. 179017), which was financed by the Ministry of Education, Science and Technological Development of the Republic of Serbia. 
outcomes. Resilient outcomes are related to numerous factors which can be classified into three domains: individual characteristics, family environment, and a wider social environment (Bonanno et al., 2015; Werner, 1990). This paper focused on the differences between adolescents with mild ID and typically developing (TD) adolescents with regard to resiliency, i.e. individual qualities which contribute to positive development outcomes.

\section{Developmental outcomes in individuals with intellectual difficulties}

The results of longitudinal studies on the differences in the psychosocial functioning of persons with borderline intelligence and mild ID compared to the normative population, indicate a relation between lower intellectual abilities and negative development outcomes. Maughan and colleagues (1999) reported that at the age of 33 persons with ID had poorer living and material circumstances, more frequent difficulties in family and marital relationships, and a higher level of affective symptomatology compared to persons without ID. Vaillant and Davis (2000) found that in adulthood men with IQs of 87 or below were more likely to complete fewer years of education, to be unskilled laborers and to have lower earnings than persons with a higher IQ. In the study on development outcomes in persons with IQs of 85 or below and their typically developing siblings, Seltzer and colleagues (2007) determined that persons with a lower IQ had limited educational, occupational and financial attainment, that they got married at an older age, that they participated less in formal organizations, and that they had higher levels of depressive symptoms and neuroticism and lower levels of sense of personal growth and life purpose.

\section{Intellectual Abilities and Resiliency}

In papers on resilience, intellectual abilities are often related to the quality of psychosocial functioning. A higher IQ and more developed cognitive skills (e.g. problem solving skills, executive functioning skills) are considered a protective factor which contributes to positive development of children exposed to unfavorable living circumstances. This thesis was confirmed by the results of studies on diverse at-risk groups, such as: children of people diagnosed as mentally ill (Rutter, 1985), maltreated children (Kaufman \& Zigler, 1989), children reared in poverty (Garmezy, 1993), and children with perinatal complications and adverse rearing conditions (Werner, 1993). It is believed that children with better intellectual and cognitive abilities can assess a stressful situation more accurately, develop coping strategies, and obtain necessary help from others (Werner, 1990). Similarly, a higher IQ can have a protective function due to its relation to better academic achievement (Masten et al., 1990).

However, intellectual abilities do not predict positive adaptation consistently. Some authors found that better intellectual abilities contributed to resilient outcomes when stress was low, but at high stress levels, more intelligent children functioned similarly to their peers with lower intellectual abilities (Luthar, 1991; Sameroff \& Rosenblum, 2006). It is hypothesized that high IQ children are more sensitive to their environments and therefore more susceptible to negative influences (Luthar, 1991). 
The results of some studies indicated that the relation between intellectual abilities and individual qualities which contributed to resilient outcomes was negative or insignificant (Avci et al., 2013; Friborg et al., 2005). Furthermore, the findings of the abovementioned longitudinal studies on psychosocial development of persons with ID pointed to significant differences among them with regard to development outcomes. Individual factors associated with more successful psychosocial functioning of persons with ID were better social and emotional competence in terms of generativity, use of adaptive defenses and capacity for warm object relations (Vaillant \& Davis, 2000). Studies conducted on samples of adolescents with ID revealed that positive individual characteristics (e.g. optimism, self-efficacy) were a good predictor of higher quality of life (Biggs \& Carter, 2016) and life satisfaction (Shogren et al., 2006).

The aim of this research was to determine the differences between adolescents with mild ID and their TD peers in resiliency domains singled out and described by Prince Embury (2007): sense of mastery, sense of relatedness, and emotional reactivity. Sense of mastery includes three individual qualities: optimism, self-efficacy and adaptability. Individual qualities included in the sense of relatedness are: sense of trust, perceived access to support, comfort with others, and tolerance of differences. Emotional reactivity includes sensitivity and recovery and impairment after emotional excitement.

The results of research by Gilmore and colleagues (2013) confirmed the presence of differences between children with ID and their typically developing peers in the abovementioned resiliency domains, in terms of lower tolerance and higher sensitivity in children with ID. This research examined the differences in resiliency between adolescents with and without ID, as well as the relation of the described individual qualities to gender and age.

\section{Research Methodology}

\section{Participants}

The sample included 864 participants of both genders, 13-19 years of age. The total sample was divided into a subsample of adolescents with mild ID (55 boys and 37 girls) and a subsample of TD adolescents ( 419 boys and 353 girls). Adolescents with mild ID were recruited from four schools for students with disabilities. The research included adolescents with intellectual functioning at the level of mild ID (IQ =50-69), with adequate verbal skills, who were assessed as capable of giving responses on a Likert-type scale. Adolescents with dual diagnoses and multiple disabilities were not included. The subsample of TD adolescents included students of eight regular elementary and secondary schools. Every school participated with four randomly selected complete classes, ranging from seventh to twelfth grades.

There was no statistically significant difference determined between participants with mild ID and TD participants with regard to gender (Chi square $=1,007 ; d f=1 ; p=0,316$ ) and age $(M=15,86 ; S D=1,843$ against $M=16,07 ; S D=1,464 ; t=1,067 ; d f=105,132 ; p=0,289)$. 


\section{Data collection}

Data on participants' age, gender, intellectual functioning, and health were taken from school records.

The Peabody Picture Vocabulary Scale - PPVT-IV (Dunn \& Dunn, 2007) was used for the assessment of verbal abilities of adolescents with mild ID. Form A was applied in this research, with 114 items divided into 16 sets which test the knowledge of nouns, verbs, and adjectives from 20 different areas (e.g. plants, professions). Class teachers selected students with adequate verbal abilities who were able to participate in the research. Also, before giving out the questionnaires, assessment of receptive speech was conducted by means of PPVT-IV. The participants with mild ID achieved standard scores in the range 94-185 ( $M=137,35 ; S D=22,794)$.

The Resiliency Scales for Children and Adolescents - RSCA (Prince Embury, 2007) consisted of 64 questions distributed across the following three scales: the Sense of Mastery Scale (MAS) consisting of Optimism, Self-Efficacy and Adaptability subscales; the Sense of Relatedness Scale (REL) consisting of Sense of Trust, Perceived Access to Support, Comfort with Others and Tolerance of Differences subscales; and the Emotional Reactivity Scale (REA) consisting of Sensitivity, Recovery and Impairment subscales. Higher scores on the MAS and REL scales, and lower scores on the REA scale point to greater resiliency. The coefficient alpha values for the scales and subscales were as follows: MAS 0,832; Optimism 0,814; Self-Efficacy 0,885; Adaptability 0,662; REL 0,909; Trust 0,788; Support 0,793; Comfort 0,763; Tolerance 0,741; REA 0,901; Sensitivity 0,770; Recovery 0,706; Impairment 0,881.

\section{Procedure}

Informed consent was obtained from the school, parents, and participants for the purpose of this research. Research aims were explained and instructions on the data collecting procedure were given to each participant. The participants were informed that participation in the research was voluntary and that their responses were confidential. The questionnaire was given to TD adolescents in groups and they completed it during school classes. The testing of adolescents with ID was conducted in a separate room in the school. The questions were read as they were given in questionnaires, with additional explanations where necessary. The participants were required to choose one of the given answers. Cards with provided answers were made in order to make it easier for the participants to answer the questions.

\section{Research Results}

The means and standard deviations for the RSCA are presented in Table 1.A high, statistically significant difference between participants with mild ID and TD participants was found on the MAS scale in total and its subscales. TD participants achieved significantly higher scores on the MAS scale in total, as well as on the Optimism and Self-efficacy subscales. Eta squared values indicate that the effect size was very high. On the other hand, participants with mild ID achieved significantly higher scores on the Adaptability 
subscale, though with rather small effect size. There was no statistically significant difference determined between participants with mild ID and TD participants on the Trust subscale. On all other subscales of the REL scale, including the scale in total, TD participants achieved significantly higher scores. However, the effect size was small. No statistically significant difference was found in mean values of the scores on the REA scale and its subscales with regard to the level of intellectual functioning. The only exception was the Recovery subscale, on which persons with mild ID achieved significantly higher scores. However, the effect size was very small.

Table 1. Results of the participants on RSCA with regard to the level of intellectual functioning

\begin{tabular}{|c|c|c|c|c|c|c|c|}
\hline \multirow{2}{*}{$\begin{array}{l}\text { Scales and } \\
\text { Subscales }\end{array}$} & \multicolumn{2}{|c|}{ TD Adolescents } & \multicolumn{2}{|c|}{ Adolescents with ID } & \multirow{2}{*}{ t } & \multirow{2}{*}{$d f$} & \multirow{2}{*}{$\mathrm{Eta}^{2}$} \\
\hline & Mean & SD & Mean & SD & & & \\
\hline MAS & 57,96 & 11,997 & 50,65 & 8,249 & $7,597^{* * *}$ & 141,589 & 0,063 \\
\hline Optimism & 18,99 & 5,315 & 17,51 & 3,627 & $3,499^{* * * *}$ & 142,436 & 0,014 \\
\hline Self-efficacy & 30,19 & 6,101 & 23,75 & 5,139 & $9,725^{* * * *}$ & 862 & 0,098 \\
\hline Adaptability & 8,78 & 2,859 & 9,39 & 1,833 & $-2,829^{* * *}$ & 149,888 & 0,006 \\
\hline REL & 76,33 & 14,164 & 71,50 & 10,242 & $4,082^{* * *}$ & 136,375 & 0,019 \\
\hline Trust & 21,37 & 4,821 & 20,72 & 3,329 & 1,670 & 141,120 & - \\
\hline Support & 20,98 & 4,051 & 19,67 & 2,867 & $3,913^{* * * *}$ & 138,504 & 0,017 \\
\hline Comfort & 12,61 & 3,080 & 11,47 & 2,351 & $4,243^{* * *}$ & 131,377 & 0,020 \\
\hline Tolerance & 21,38 & 4,877 & 19,64 & 3,859 & $3,963^{* * * *}$ & 128,384 & 0,018 \\
\hline REA & 31,79 & 14,723 & 33,11 & 14,118 & $-0,814$ & 862 & - \\
\hline Sensitivity & 12,31 & 5,268 & 11,89 & 4,451 & 0,845 & 123,507 & - \\
\hline Recovery & 4,57 & 3,563 & 5,50 & 3,080 & $-2,392^{*}$ & 862 & 0,006 \\
\hline Impairment & 14,91 & 8,635 & 15,72 & 8,582 & $-0,853$ & 862 & - \\
\hline
\end{tabular}

${ }^{*} p \leq 0,05 ;{ }^{* *} p \leq 0,01 ;{ }^{* * *} p \leq 0,001$

Table 2 presents gender differences in the RSCA scores for both subsamples. On the MAS scale in total, as well as on all subscales, TD girls achieved statistically significantly higher scores than boys. Except on the Optimism subscale, where the effect size was moderate to high (Eta squared $=0,06$ ), the difference between the mean values of scores on Self-efficacy (Eta squared $=0,018$ ) and Adaptability (Eta squared $=0,032$ ) subscales, and the MAS scale in total (Eta squared $=0,022$ ) was small. TD girls achieved significantly higher scores on the REL scale and Trust, Support, and Tolerance subscales. The difference between the mean values of the compared groups was moderate on the Support subscale (Eta squared $=0,06$ ), and low on the Trust (Eta squared $=0,01$ ) and Tolerance (Eta squared $=0,03$ ) subscales, as well as on the REL scale in total (Eta squared $=0,03$ ). TD girls achieved statistically significantly higher scores than boys only on the Sensitivity subscale of the REA scale. The difference between the mean values of scores was small (Eta squared $=0,01)$. 
In the subsample of adolescents with mild ID, no statistically significant gender differences were found in the mean values of scores on the RSCA scales and subscales.

Table 2. Results of the participants on RSCA with regard to gender

\begin{tabular}{lcccccc}
\hline \multirow{2}{*}{$\begin{array}{l}\text { Scales and } \\
\text { Subscales }\end{array}$} & \multicolumn{3}{c}{ TD Adolescents } & \multicolumn{3}{c}{ Adolescents with ID } \\
\cline { 2 - 6 } MAS & Goyrls & $\mathrm{t}$ & Boys & Girls & $\mathrm{t}$ \\
\hline Optimism & 56,36 & 59,87 & $-4,164^{* * *}$ & 50,89 & 50,30 & 0,337 \\
Self-efficacy & 18,60 & 19,46 & $-2,286^{*}$ & 17,82 & 17,05 & 0,991 \\
Adaptability & 29,44 & 31,09 & $-3,772^{* * *}$ & 23,45 & 24,19 & $-0,670$ \\
REL & 8,32 & 9,32 & $-5,020^{* * *}$ & 9,62 & 9,05 & 1,456 \\
Trust & 74,10 & 78,97 & $-4,943^{* * *}$ & 71,29 & 71,81 & $-0,238$ \\
Support & 20,93 & 21,89 & $-2,803^{* * *}$ & 20,60 & 20,89 & $-0,410$ \\
Comfort & 20,07 & 22,05 & $-7,160^{* * *}$ & 19,65 & 19,70 & $-0,079$ \\
Tolerance & 12,45 & 12,79 & $-1,528$ & 11,35 & 11,65 & $-0,604$ \\
REA & 20,65 & 22,24 & $-4,657^{* * *}$ & 19,69 & 19,57 & 0,150 \\
Sensitivity & 31,26 & 32,43 & $-1,113$ & 34,76 & 30,65 & 1,378 \\
Recovery & 11,84 & 12,88 & $-2,767^{* *}$ & 12,09 & 11,59 & 0,522 \\
Impairment & 4,48 & 4,68 & $-0,748$ & 5,65 & 5,27 & 0,585 \\
\hline
\end{tabular}

${ }^{*} p \leq 0,05 ;{ }^{* *} p \leq 0,01 ;{ }^{* * *} p \leq 0,001$

According to the results presented in Table 3, a statistically significant difference was found in the mean values of scores on all RSCA scales and subscales among TD participants of different ages. The results of the Tukey post hoc test indicate that on the MAS and REL scales and their subscales, 13-year-old participants had higher scores than all groups of participants aged between 15 and 18, and that 14-year-old participants had higher scores than all older participants. The effect size was moderate to high. A difference between younger and older participants was also determined on the REA scale, though with rather small effect size. On the Sensitivity and Impairment subscales, 13 and 14-year-old participants had higher scores than the oldest group of participants in the sample. On the Recovery subscale, 13-year-old participants had higher scores than all older participants; 14-year-old participants had, on average, significantly higher scores than participants who were 15,16 , and 18 years old.

On the other hand, in participants with mild ID, a statistically significant difference in the mean values of scores among participants of different ages was found only on the Optimism subscale of the MAS scale. The effect size was moderate to high. The post hoc Tukey test determined that the youngest participants had lower scores than the oldest participants. 
Table 3. Results of the participants on RSCA with regard to age

\begin{tabular}{lcccc}
\hline \multirow{2}{*}{ Scales and Subscales } & \multicolumn{2}{c}{ TD Adolescents } & \multicolumn{2}{c}{$\begin{array}{c}\text { Adolescents with ID } \\
\mathrm{df}=5,766\end{array}$} \\
\cline { 2 - 5 } & $\mathrm{F}$ & $\mathrm{Eta}^{2}$ & $\mathrm{~F}$ & Eta $^{2}$ \\
\hline MAS & $32,273^{* * * *}$ & 0,21 & 2,202 & - \\
\hline Optimism & $25,919^{* * * *}$ & 0,17 & $3,159^{*}$ & 0,06 \\
Self-efficacy & $25,528^{* * * *}$ & 0,17 & 1,381 & - \\
Adaptability & $9,782^{* * *}$ & 0,06 & 0,527 & - \\
REL & $24,770^{* * *}$ & 0,16 & 0,507 & - \\
Trust & $17,697^{* * *}$ & 0,12 & 0,316 & - \\
Support & $13,284^{* * *}$ & 0,09 & 1,361 & - \\
Comfort & $12,307^{* * *}$ & 0,08 & 0,549 & - \\
Tolerance & $23,115^{* * *}$ & 0,15 & 1,663 & - \\
REA & $6,867^{* * *}$ & 0,04 & 1,380 & - \\
Sensitivity & $2,850^{*}$ & 0,02 & 0,375 & - \\
Recovery & $7.512^{* * *}$ & 0.05 & 1.662 & - \\
Impairment & $5.393^{* * *}$ & 0.03 & 1.722 & - \\
\hline
\end{tabular}

${ }^{*} p \leq 0,05 ;{ }^{* * *} p \leq 0,001$

\section{Discussion}

The results of this research indicate that adolescents with mild ID differ from TD adolescents with regard to individual characteristics which contribute to resilient outcomes. In general, adolescents with mild ID reported a lower sense of mastery and sense of relatedness and elevated emotional reactivity compared to their TD peers.

With regard to sense of mastery, a significantly lower level of optimism and self-efficacy, and a significantly higher level of adaptability, were observed in adolescents with mild ID compared to TD adolescents. The results of previous studies indicated that there was a positive correlation of intellectual and cognitive abilities with optimism (Klaczynski \& Fauth, 1996; Nonis \& Wright, 2003) and self-efficacy (Chamorro Premuzic et al., 2010; Paunonen \& Hong, 2010) in TD adolescents. The obtained findings are in accordance with the results of other comparative studies which confirmed that persons with ID were less optimistic (Biggs \& Carter, 2016) and felt significantly less self-efficacious than their non-disabled peers (Forte et al., 2011). Zigler and associates (1999) reported that persons with ID were more dependent on adults, that their expectations of success in solving tasks were low, and that they were less interested in new situations. The/A lower level of sense of mastery in persons with ID is usually related to a past history of failure experiences (Gresham et al., 1988; Zigler et al., 1999). Bearing in mind that Gilmore and colleagues (2013) did not find significant differences in the sense of mastery level between children 
with and without ID, it can be assumed that these differences become conspicuous at an older age and that they are related to accumulated failure experiences, limited possibilities for acquiring new experiences, and more objective self-assessment. The results which refer to differences in adaptability deviate from the general pattern of a lower sense of mastery in adolescents with mild ID, although a very small effect size was determined.

Adolescents with mild ID also significantly differ from their TD peers with regard to individual qualities in the sense of relatedness domain. The results which indicate a lower level of perceived access to support in adolescents with mild ID can be compared to the findings of comparative studies on significantly lower levels of perceived access to social support in persons with ID compared to persons without ID (Victorian Population Health Survey of People with an Intellectual Disability 2013, 2015; Mithen et al., 2015). Results of studies on samples of TD adolescents which show a positive correlation between intellectual abilities and perceived access to social support (Hogan et al., 2010; Sameroff et al., 1993) should also be mentioned. The findings which refer to a lower level of comfort with others in adolescents with mild ID are in accordance with the observations of other authors on the difficulties which persons with ID have in social relations. On the basis of a systematic review of literature in this area, Verdonschot and colleagues (2009) concluded that persons with ID had less contact with family and friends, and that their social networks were relatively small, mainly consisting of persons with ID. Furthermore, research on peer interactions of students with ID in regular schools indicated that they socialized with peers with ID more than with TD peers (Cutts \& Sigafoos, 2001), that they were poorly accepted by their peers (Smoot, 2004), that they were less popular, had fewer friends, and were rarely included in friend groups (Koster et al., 2010). A lower level of tolerance of differences was determined in adolescents with mild ID, i.e. a belief that they can safely express differences in relationships. Gilmore and colleagues (2013) also reported on the lower level of tolerance in participants with ID, and explained that it was as a complex skill which required a high level of social competence. In support of this explanation, we can cite the results of studies on the lower social competence of children and adolescents with ID compared to their TD peers (Bramlett et al., 1994; Kucuker \& Cifci Tekinarslan, 2015).

In the emotional reactivity domain, the difference between adolescents with mild ID and TD adolescents was determined only with regard to recovery skills. Adolescents with mild ID had a lower capacity to return to normal functioning after a strong emotional reaction. The obtained results differ from the results of Gilmore and colleagues (2013), which indicated that participants with ID had a higher level of emotional sensitivity, but did not differ with regard to recovery skills. However, Gilmore and colleagues (2013) pointed out that their findings were unexpected, bearing in mind that emotional problems were more frequent in persons with ID. The results obtained in this research are in accordance with the findings of comparative studies on poorer self-regulation skills (Eisenhower et al., 2007; Willson, 1999) and a generally higher incidence of emotional problems (Dekker et al., 2002; Emerson, 2003) in adolescents with ID compared to their TD peers.

The results of this research indicated that gender differences in the examined individual qualities were less pronounced in adolescents with mild ID than their TD peers. In the subsample of TD adolescents, girls had a significantly higher level of sense of mastery in general, as well as a significantly higher level of all individual qualities in this domain, 
than boys. Furthermore, TD girls had a significantly higher level of sense of relatedness and a higher level of three out of four examined individual qualities in this domain -sense of trust, perceived access to support and tolerance of differences, compared to TD boys. With regard to emotional reactivity, TD boys and girls differed only in sensitivity which was significantly higher in girls. Prince Embury (2007) found the same general direction of gender differences in the standardization sample, manifested as higher scores on all scales (MAS, REL, and REA) in girls, with significant differences only in adaptability and perceived support at the ages 12-14. The findings which refer to gender differences in sense of mastery in TD adolescents are consistent with the results of other studies on samples of TD adolescents which indicated that girls had a higher level of self-efficacy (Banduraet al., 2003; Britner \& Pajares, 2001) and optimism (Wray et al.,2013; Yates, 2002). Bearing in mind that the questions in the Adaptability subscale mainly referred to seeking help when needed, the obtained results can be compared to the findings of research on coping strategies in adolescence, which indicated that girls used this strategy more frequently (Eschenbeck et al., 2007; Hampel \& Petermann, 2005). The results regarding gender differences in sense of relatedness in TD adolescents were confirmed by empirical data on the higher level of attachment (Laible et al., 2000; Muris et al., 2003) and perceived social support (Hogan et al., 2010; Malecki \& Demaray, 2002), as well as the lower level of loneliness (Cheng \& Furnham, 2002; Chipuer \& Pretty, 2007) in girls compared to boys from the typical population. Also, the results which refer to a higher level of emotional reactivity, i.e. sensitivity, in TD girls are in accordance with findings of other authors regarding higher intensity and negativity of emotional reactions to stressful events in girls (Charbonneau et al., 2009; Laible et al., 2010).

In adolescents with mild ID, no significant gender differences were determined in sense of mastery, sense of relatedness, and emotional reactivity. Gilmore and colleagues (2013) also examined the influence of gender on the RSCA scores and found no significant differences except that girls reported higher sensitivity than boys. With regard to individual qualities in the sense of mastery domain, the obtained results are in accordance with the findings of other authors indicating that there were no significant gender differences in self-efficacy in persons with ID (Gresham et al., 1988; Payne \& Jahoda, 2004). Nota and associates (2010) explained the lack of differences in self-efficacy beliefs in male and female persons with ID by the fact that school and extra scholastic activities for individuals with ID were rarely differentiated by gender, and thus girls and boys with ID mainly had similar experiences. The results of this research which refer to individual qualities in the sense of relatedness domain, are consistent with the findings of other authors indicating that in children and adolescents with ID gender was not significantly related to peer acceptance and relations (Smoot, 2004; Wendelborg \& Kvello, 2010) or social skills (Adeniyi \& Omigbodun, 2016; Heiman \& Margalit, 1998). This is further supported by empirical findings that academic competence, physical appearance and behavior problems had more influence on the status of persons with ID in their peer group than gender (Baydik \& Bakkaloğlu, 2009).In this research, there were no gender differences in emotional reactivity in adolescents with ID, which corresponds to the findings of other studies indicating that boys and girls with ID did not differ with regard to the incidence of emotional problems (Dekker \& Koot, 2003; Einfeld \& Tonge, 1996). This is in accordance with observations of 
some authors that neurological impairments and deficits in basic skills had a more significant role than gender in the etiology of emotional problems in children and adolescents with ID (Chadwick et al., 2000; Einfeld \& Tonge, 1996).

Significant age differences were determined in the subsample of TD adolescents. Younger TD adolescents reported more sense of mastery, sense of relatedness, and emotional reactivity than older TD adolescents. The general direction of the determined age differences is in accordance with the findings of Prince Embury (2007) for the standardization sample. However, she reported on significant differences only with regard to the Impairment score which is higher at a younger than at an older age. Results of other studies conducted on samples of TD adolescents indicated that self-efficacy (Jacobs et al., 2002; Pajares \& Valiante, 1999) and optimism (Carvajal et al., 2002, Patton et al., 2011) decreased with age, and that seeking help as a coping strategy occurred earlier than more complex strategies requiring more developed cognitive abilities (Compas et al., 2001; Hampel \& Petermann, 2005). With regard to sense of relatedness in TD adolescents, previous studies also indicated that younger adolescents had a higher level of attachment (Laible et al., 2000; Muris et al., 2003) and perceived social support (Malecki \& Demaray, 2002; Scholte et al., 2001), as well as a lower level of loneliness (Brage et al., 1993; Chipuer \& Pretty, 2007) compared to older adolescents. The obtained results which point to age differences in emotional reactivity in TD adolescents are consistent with findings of other authors according to which emotional reactivity decreased (Silket al., 2003), and emotion regulation increased (Silvers et al., 2012) with age.

On the other hand, in the subsample of adolescents with mild ID, significant age differences were determined only in the level of optimism. However, the direction of these differences was opposite to the one in TD adolescents, since younger adolescents with mild ID had a lower level of optimism than older ones. In a meta-analytic review of studies on self-serving attributional bias, Mezulis and colleagues (2004) concluded that, in the general population, the level of positivity bias in attributions was the lowest in early adolescence (12-14 years of age) when a person starts realizing that frequent failures can be the result of lower abilities. The obtained findings indicating the absence of significant age differences in self-efficacy are supported by the results of previous studies (Gresham et al., 1988; Payne \& Jahoda, 2004). Similarly, the results which refer to sense of relatedness are consistent with the findings of other authors according to which, in persons with ID, there were no significant age differences in social skills (Adeniyi \& Omigbodun, 2016; Heiman \& Margalit, 1998), peer acceptance and relations (Heiman \& Margalit, 1998; Wendelborg \& Kvello, 2010), and perceived social support (Lunsky \& Benson, 2001).In interpreting these findings, Nota and colleagues (2007) made a significant observation that the limited experiences and opportunities that hinder individual qualities of people with ID override any age-related effects. The findings which refer to emotional reactivity are confirmed by the results of other studies which indicated that there were no age differences with regard to emotional problems in children and adolescents with ID (Einfeld \& Tonge, 1996). The absence of age differences in the prevalence of emotional problems in this population is associated with a slower development of behavioral regulation, as well as with the influence of neurological and genetic factors (Dekker \& Koot, 2003). 


\section{Limitations of the study}

The current study has several limitations that should be taken into account. The ID subsample size was relatively small and composed of 'special' school students with mild ID, so replication with a larger number of adolescents with different degrees of ID is desirable. Data obtained from adolescents with ID were used in this research. Even though special attention was given to assessing the verbal abilities of adolescents with ID and adapting the assessment procedure accordingly, it is possible they were not able to, or did not want to give correct answers to some questions. In the future, it would be important to replicate the present findings using multiple informants. This study included the questions covered by the Resiliency Scales for Children and Adolescents, so we have no data on other individual characteristics related to resilient outcomes. Apart from that, the obtained results refer to individual characteristics which represent only one aspect of the complex resilience construct. Thus, future studies should be directed at environmental influences and the interaction of individual and environmental factors.

\section{Conclusion}

A general conclusion of this research is that adolescents with mild ID have a lower level of resiliency than TD adolescents. It was found that adolescents with mild ID have significantly lower levels of sense of mastery and sense of relatedness and a higher level of emotional reactivity. In light of these findings, it can be stated that implementing effective interventions to promote resiliency may contribute to the positive adaptation of adolescents with mild ID. The results of this research complement and extend earlier studies by highlighting domains of resiliency that are less developed in adolescents with mild ID and providing impetus for attention to interventions that may address these areas. In addition, our findings underscore the need for a more careful examination of the specific constellations of individual qualities and for the development of multifaceted programs that would provide interventions for different domains of resiliency, rather than focusing on one aspect at a time. This study also provides new information indicating that the relationship between age and gender on the one hand, and individual characteristics, on the other, happened to be different in the two subsets. The gender and age differences found in all domains of resiliency in TD adolescents were not confirmed in adolescents with mild ID. In this regard, our data provides a starting point for examining the existence of different developmental pathways of resiliency in these two groups.

\section{References}

Adeniyi, Y. C. \& Omigbodun, O. O. (2016). Effect of a Classroom-Based Intervention on the Social Skills of Pupils with Intellectual Disability in Southwest Nigeria. Child and Adolescent Psychiatry and Mental Health, Vol. 10, No. 1, 1-12.

Avci, G., Hanten, G., Schmidt, A., Li, X., Orsten, K., Faber, J., Post, M. \& Newsome, M. R. (2013). Cognitive Contributors to Resilience in Youth from Underserved Populations: A Brief Report. Journal of Public Mental Health, Vol. 12, No. 3, 165-170. 
Bandura, A., Caprara, G. V., Barbaranelli, C., Gerbino, M. \& Pastorelli, C. (2003). Role of Affective SelfRegulatory Efficacy in Diverse Spheres of Psychosocial Functioning. Child Development, Vol. 74, No. 3, 769-782.

Baydik, B. \& Bakkaloğlu, H. (2009). Predictors of Sociometric Status for Low Socioeconomic Status Elementary Mainstreamed Students with and without Special Needs. Educational Sciences: Theory \& Practice, Vol. 9, No. 2, 435-447.

Biggs, E. E. \& Carter, E. W. (2016). Quality of Life for Transition-Age Youth with Autism or Intellectual Disability. Journal of Autism and Developmental Disorders, Vol. 46, No. 1, 190-204.

Bonanno, G. A., Romero S. A. \& Klein, S. I. (2015). The Temporal Elements of Psychological Resilience: An Integrative Framework for the Study of Individuals, Families, and Communities. Psychological Inquiry, Vol. 26, No. 2, 139-169.

Brage, D., Meredith, W. \& Woodward, J. (1993). Correlates of Loneliness among Midwestern Adolescents. Adolescence, Vol. 28, No. 111, 685-693.

Bramlett, R. K., Smith, B. L. \& Edmonds, J. (1994). A Comparison of Nonreferred, Learning-Disabled, and Mildly Mentally Retarded Students Utilizing the Social Skills Rating System. Education and Assessment, Vol. 31, No. 1, 13-19.

Britner, S. L. \& Pajares, F. (2001). Self-Efficacy Beliefs, Motivation, Race, and Gender in Middle School Science. Journal of Women and Minorities in Science and Engineering, Vol. 7, No. 4, 271-285.

Carvajal, S. C., Evans, R. I., Nash, S. G. \& Getz, J. G. (2002). Global Positive Expectancies of the Self and Adolescents' Substance Use Avoidance: Testing a Social Influence Mediational Model. Journal of Personality, Vol. 70, No. 3, 421-442.

Chadwick, O., Piroth, N., Walker, J., Bernard, S. \& Taylor, E. (2000). Factors Affecting the Risk of Behaviour Problems in Children with Severe Intellectual Disability. Journal of Intellectual Disability Research, Vol. 44, No. 2, 108-123.

Chamorro Premuzic T., Harlaar, N., Greven, C. U. \& Plomin, R. (2010). More than Just IQ: A Longitudinal Examination of Self-Perceived Abilities as Predictors of Academic Performance in a Large Sample of UK Twins. Intelligence, Vol. 38, No. 4, 385-392.

Charbonneau, A. M., Mezulis, A. H. \& Hyde, J. S. (2009). Stress and Emotional Reactivity as Explanations for Gender Differences in Adolescents' Depressive Symptoms. Journal of Youth and Adolescence, Vol. 38, No. 8, 1050-1058.

Cheng, H. \& Furnham, A. (2002). Personality, Peer Relations, and Self-Confidence as Predictors of Happiness and Loneliness. Journal of Adolescence, Vol. 25, No. 3, 327-339.

Chipuer, H. M. \& Pretty, G. H. (2007). Facets of Adolescents' Loneliness: A Study of Rural and Urban Australian Youth. Australian Psychologist, Vol. 35, No. 3, 233-237.

Compas, B. E., Connor Smith, J. K., Saltzman, H., Thomsen, A. H. \& Wadsworth, M. E. (2001). Coping with Stress During Childhood and Adolescence: Problems, Progress, and Potential in Theory and Research. Psychological Bulletin, Vol. 127, No. 1, 87-127.

Cutts, S. \& Sigafoos, J. (2001). Social Competence and Peer Interactions of Students with Intellectual Disability in an Inclusive High School. Journal of Intellectual and Developmental Disability, Vol. 26, No. 2, 127-141.

Dekker, M. C. \& Koot, H. M. (2003). DSM-IV Disorders in Children with Borderline to Moderate Intellectual Disability. I: Prevalence and Impact. Journal of American Child and Adolescent Psychiatry, Vol. 42, No. 8, 915-922.

Dekker, M. C., Koot, H. M., van der Ende, J. \& Verhulst, F. C. (2002). Emotional and Behavioral Problems in Children and Adolescents with and without Intellectual Disability. Journal of Child Psychology and Psychiatry, Vol. 43, No. 8, 1087-1098.

Dunn, L. M. \& Dunn, D. M. (2007). Peabody Picture Vocabulary Test. Minneapolis: NCS Pearson, Inc. 
Einfeld, S. L. \& Tonge, B. J. (1996). Population Prevalence of Psychopathology in Children and Adolescents with Intellectual Disability: II Epidemiological Findings. Journal of Intellectual Disability Research, Vol. 40, No. 2, 99-109.

Eisenhower, A. S., Baker, B. L. \& Blacher, J. (2007). Early Student-Teacher Relationships of Children with and without Intellectual Disability: Contributions of Behavioral, Social, and Self-Regulatory Competence. Journal of School Psychology, Vol. 45, No. 4, 363-383.

Emerson, E. (2003). Prevalence of Psychiatric Disorders in Children and Adolescents with and without Intellectual Disability. Journal of Intellectual Disability Research, Vol. 47, No. 1, 51-58.

Eschenbeck, H., Kohlmann, C. W. \& Lohaus, A. (2007). Gender Differences in Coping Strategies in Children and Adolescents. Journal of Individual Differences, Vol. 28, No. 1, 18-26.

Forte, M., Jahoda, A. \& Dagnan, D. (2011). An Anxious Time? Exploring the Nature of Worries Experienced by Young People with Mild to Moderate Intellectual Disability as They Make the Transition to Adulthood. British Journal of Clinical Psychology, Vol. 50, No. 4, 398-411.

Friborg, O., Barlaug, D., Martinussen, M., Rosenvinge, J. H. \& Hjemdal, O. (2005). Resilience in Relation to Personality and Intelligence. International Journal of Methods in Psychiatric Research, Vol. 14, No. 1, 29-42.

Garmezy, N. (1993). Children in Poverty: Resilience Despite Risk. Psychiatry, Vol. 56, No. 1, 127-136.

Gilmore, L., Campbell, M., Shochet, I. \& Roberts, C. (2013). Resiliency Profiles of Children with Intellectual Disability and Their Typically Developing Peers. Psychology in the Schools, Vol. 50, No. 10, 1032-1043.

Gresham, F. M., Evans, S. \& Elliot, S. N. (1988). Self-Efficacy Differences among Mildly Handicapped, Gifted, and Nonhandicapped Students. Journal of Special Education, Vol. 22, No. 2, 231-241.

Hampel, P. \& Petermann, F. (2005). Age and Gender Effects on Coping in Children and Adolescents. Journal of Youth and Adolescence, Vol. 34, No. 2, 73-83.

Heiman, T. \& Margalit, M. (1998). Loneliness, Depression, and Social Skills among Students with Mild Mental Retardation in Different Educational Settings. The Journal of Special Education, Vol. 32, No. 3, 154-163.

Hogan, M. J., Parker, J. D. A., Wiener, J., Watters, C., Wood, L. M. \& Oke, A. (2010). Academic Success in Adolescence: Relationships among Verbal IQ, Social Support and Emotional Intelligence. Australian Journal of Psychology, Vol. 62, No. 1, 30-41.

Jacobs, J. E., Lanza, S., Osgood, D. W., Eccles, J. S. \& Wigfield, A. (2002). Changes in Children's SelfCompetence and Values: Gender and Domain Differences across Grades one Through Twelve. Child Development, Vol. 73, No. 2, 509-527.

Kaufman, J. \& Zigler, E. (1989). The Intergenerational Transmission of Child Abuse. In D. Cicchetti \& V. Carlson (Eds.), Child Maltreatment: Theory and Research on the Causes and Consequences of Child Abuse and Neglect (pp. 129-150). New York: Cambridge University Press.

Klaczynski, P. A. \& Fauth, J. M. (1996). Intellectual Ability, Rationality, and Intuitiveness as Predictors of Warranted and Unwarranted Optimism for Future Life Event. Journal of Youth and Adolescence, Vol. 25, No. 6, 755-773.

Koster, M., Pijl, S. J., Nakken, H. \& Van Houten, E. (2010). Social Participation of Students with Special Needs in Regular Primary Education in the Netherlands. International Journal of Disability, Development, and Education, Vol. 57, No. 1, 59-75.

Kucuker, S. \& CifciTekinarslan, I. (2015). Comparison of the Self-Concepts, Social Skills, Problem Behaviors, and Loneliness Levels of Students with Special Needs in Inclusive Classrooms. Educational Sciences: Theory and Practice, Vol. 15, No. 6, 1559-1573.

Laible, D. J., Carlo, G. \& Raffaelli, M. (2000). The Differential Relations of Parent and Peer Attachment to Adolescent Adjustment. Journal of Youth and Adolescence, Vol. 29, No. 1, 45-59. 
Laible, D., Carlo, G., Panfile, T., Eye, J. \& Parker, J. (2010). Negative Emotionality and Emotion Regulation: A Person-Centered Approach to Predicting Socioemotional Adjustment in Young Adolescents. Journal on Research in Personality, Vol. 44, No. 5, 621-629.

Lunsky, Y. \& Benson, B. A. (2001). Association between Perceived Social Support and Strain, and Positive and Negative Outcome for Adults with Mild Intellectual Disability. Journal of Intellectual Disability Research, Vol. 45, No. 2, 106-114.

Luthar, S. S. (1991).Vulnerability and Resilience: A Study of High-Risk Adolescents. Child Development, Vol. 62, No. 3, 600-616.

Luthar, S. S., Crossman, E. J. \& Small, P. J. (2015). Resilience and Adversity. In L. M. Lerner \& M. E. Lamb (Eds.), Handbook of Child Psychology and Development Science (pp. 247-286). New York: Wiley.

Malecki, C. K. \& Demaray, M. K. (2002). Measuring Perceived Social Support: Development of the Child and Adolescent Social Support Scale (CASSS). Psychology in the Schools, Vol. 39, No. 1, 1-18.

Masten, A. S., Best, K. M. \& Garmezy, N. (1990). Resilience and Development: Contributions from the Study of Children Who Overcome Adversity. Development and Psychopathology, Vol. 2, No. 4, 425-444.

Maughan, B., Collishaw, S.\& Pickles, A. (1999). Mild Mental Retardation: Psychosocial Functioning in Adulthood. Psychological Medicine, Vol. 29, No. 2, 351-366.

Mezulis, A. H., Abramson, L. Y., Hyde, Y. S. \& Hankin, B. L. (2004). Is There a Universal Positivity Bias in Attributions? A Meta-Analytic Review of Individual, Developmental, and Cultural Differences in the Self-Serving Attributional Bias. Psychological Bulletin, Vol. 130, No. 5, 711-747.

Mithen, J., Aitken, Z., Ziersch, A. \& Kavanagh, A. M. (2015). Inequalities in Social Capital and Health between People with and without Disabilities. Social Science \& Medicine, Vol. 116, No. 1, 26-35.

Muris, P., Meesters, C. \& van den Berg, S. (2003). Internalizing and Externalizing Problems as Correlates of Self-Reported Attachment Style and Perceived Parental Rearing in Normal Adolescents. Journal of Child and Family Studies, Vol. 12, No. 2, 171-183.

Nonis, S. A. \&Wright, D. (2003). Moderating Effects of Achievement Striving and Situational Optimism on the Relationship between Ability and Performance Outcomes of College Students. Research in Higher Education, Vol. 44, No. 3, 327-346.

Nota, L., Ferrari, L., Soresi, S. \& Wehmeyer, M. L. (2007). Self-Determination, Social Abilities, and the Quality of Life of People with Intellectual Disability. Journal of Intellectual Disability Research, Vol. 51 , No. 11, 850-865.

Nota, L., Ginevra, M. C. \& Carrieri, L. (2010). Career Interests and Self-Efficacy Beliefs Among Young Adults with an Intellectual Disability. Journal of Policy and Practice in Intellectual Disabilities, Vol. 7, No. 4, 250-260.

Pajares, F. \& Valiante, G. (1999). Grade Level and Gender Differences in the Writing Self-Beliefs of Middle School Students. Contemporary Educational Psychology, Vol. 24, No. 4, 390-405.

Patton, G. C., Tollit, M. M., Romaniuk, H., Spence, S. H., Sheffield, H. \& Sawyer, M. G. (2011). A Prospective Study of the Effects of Optimism on Adolescent Health Risks. Pediatrics, Vol. 127, No. 2, 308-316.

Paunonen, S. V. \& Hong, R. Y. (2010). Self-Efficacy and the Prediction of Domain-Specific Cognitive Abilities. Journal of Personality, Vol. 78, No. 1, 339-359.

Payne, R. \& Jahoda, A. (2004). The Glasgow Social Self-Efficacy Scale - A New Scale for Measuring Social Self-Efficacy in People with Intellectual Disability. Clinical Psychology and Psychotherapy, Vol. 11, No. 4, 265-274.

Prince Embury, S. (2007). Resiliency Scales for Children and Adolescents: A Profile of Personal Strengths. San Antonio: Harcourt Assessment.

Rutter, M. (1985). Resilience in the Face of Adversity: Protective Factors and Resistance to Psychiatric Disorder. British Journal of Psychiatry, Vol. 147, No. 6, 598-611. 
Sameroff, A. J. \& Rosenblum, K. L. (2006). Psychosocial Constraints on the Development of Resilience. Annals of the New York Academy of Sciences, Vol. 1094, No. 1, 116-124.

Sameroff, A. J., Seifer, R., Baldwin, A. \& Baldwin, C. (1993). Stability of Intelligence from Preschool to Adolescence: The Influence of Social and Family Risk Factors. Child Development, Vol. 60, No. 1, 80-97.

Scholte, R. H. J., van Lieshout, C. F. M. \& van Aken, M. A. G. (2001). Perceived Relational Support in Adolescence: Dimensions, Configurations, and Adolescent Adjustment. Journal of Research on Adolescence, Vol. 11, No. 1, 71-94.

Seltzer, M. M., Floyd, F., Greenberg, J., Lounds, J., Lindstrom, M. \& Hong, J. (2007). Life Course Impact of Mild Intellectual Deficits. American Journal on Mental Retardation, Vol. 110, No. 6, 451-468.

Shogren, K. A., Lopez, S. J., Wehmeyer, M. L., Little, T. D. \& Pressgrove, C. L. (2006). The Role of Positive Psychology Constructs in Predicting Life Satisfaction in Adolescents with and without Cognitive Disabilities: An Exploratory Study. Journal of Positive Psychology, Vol. 1, No. 1, 37-52.

Silk, J. S., Steinberg, L. \& Morris, A. S. (2003). Adolescents' Emotion Regulation in Daily Life: Links to Depressive Symptoms and Problem Behavior. Child Development, Vol. 74, No. 6, 1869-1880.

Silvers, J. A., McRae, K., Gabrieli, J. D. E., Gross, J. J., Remy, K. A. \& Ochsner, K. N. (2012). Age-Related Differences in Emotional Reactivity, Regulation, and Rejection Sensitivity in Adolescence. Emotion, Vol. 12, No. 6, 1235-1247.

Smoot, S. L. (2004). An Outcome Measure for the Social Goals of Inclusion. Rural Special Education Quarterly, Vol. 23, No. 3, 15-22.

Vaillant, G. E. \& Davis, J.T. (2000). Social/Emotional Intelligence and Midlife Resilience in Schoolboys with Low Tested Intelligence. American Journal of Orthopsychiatry, Vol. 70, No. 2, 215-222.

Verdonschot, M. M. L., de Witte, L. P., Reichrath, E., Buntinx, W. H. E. \& Curfs, L. M. G. (2009). Community Participation of People with an Intellectual Disability: A Review of Empirical Findings. Journal of Intellectual Disability Research, Vol. 53, No. 4, 303-318.

Victorian Population Health Survey of People with an Intellectual Disability 2013 (2015). Melbourne: Department of Health \& Human Services, State Government of Victoria.

Wendelborg, C. \& Kvello, Ø. (2010). Perceived Social Acceptance and Peer Intimacy among Children with Disabilities in Regular Schools in Norway. Journal of Applied Research in Intellectual Disabilities, Vol. 23, No. 2, 143-153.

Werner, E. E. (1990). Protective Factors and Individual Resilience. In J. P. Shonkoff \& S. J. Meisels (Eds.), Handbook of Early Childhood Intervention (pp. 115-132). New York: Cambridge University Press.

Werner, E. E. (1993). Risk, Resilience, and Recovery: Perspectives from the Kauai Longitudinal Study. Development and Psychopathology, Vol. 5, No. 4, 503-515.

Willson, B. J. (1999). Entry Behavior and Emotion Regulation Abilities of Developmentally Delayed Boys. Developmental Psychology, Vol. 35, No. 1, 214-222.

Wray, T. B., Dvorak, R. D., Hsia, J. F., Arens, A. M. \& Schweinle, W. E. (2013). Optimism and Pessimism as Predictors of Alcohol Use Trajectories in Adolescence. Journal of Child \& Adolescent Substance Abuse, Vol. 22, No. 1, 58-68.

Yates, S. M. (2002). The Influence of Optimism and Pessimism on Student Achievement in Mathematics. Mathematics Education Research Journal, Vol. 14, No. 1, 4-15.

Zigler, E., BennettGates, D. \& Hodapp, R. (1999). Assessing Personality Traits of Individuals with Mental Retardation. In E. Zigler \& D. Bennett-Gates (Eds.), Personality Development in Individuals with Mental Retardation (pp. 206-225). New York: Cambridge University Press.

Примљено: 25. 08. 2017.

Прихваћено за штампу: 26. 09. 2017. 


\title{
КОМПАРАЦИЈА ИНДИВИДУАЛНИХ КВАЛИТЕТА РЕЗИЛИЈЕНТНОСТИ АДОЛЕСЦЕНАТА СА ИНТЕЛЕКТУАЛНОМ ОМЕТЕНОШЋУ И АДОЛЕСЦЕНАТА ТИПИЧНОГ РАЗВОЈА
}

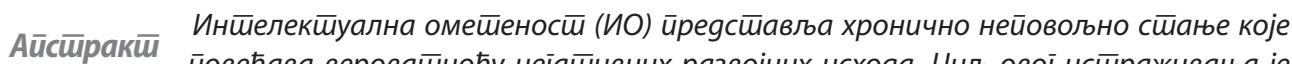

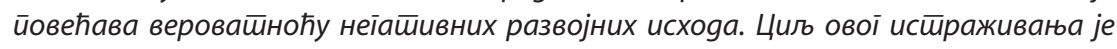

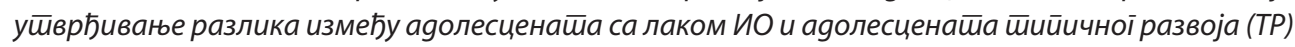

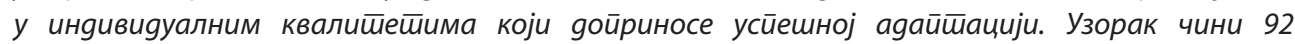

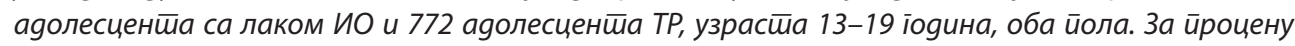

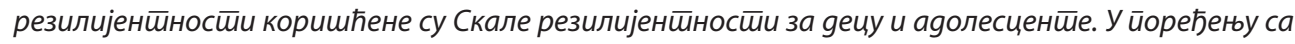

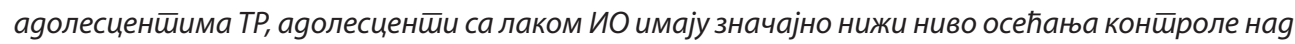

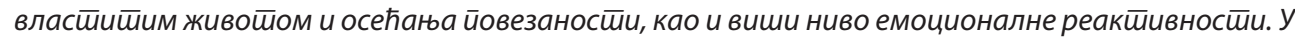

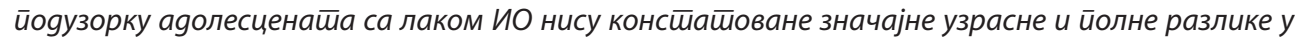

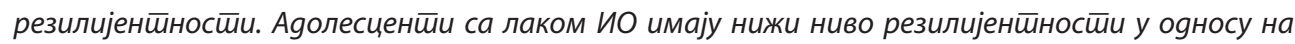

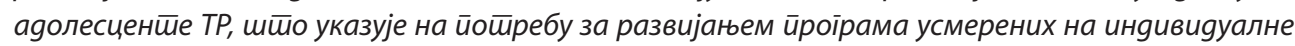

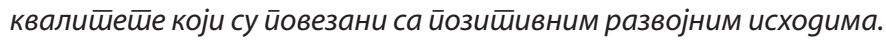

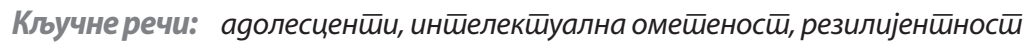

\section{СРАВНЕНИЕ ИНДИВИДУАЛЬНЫХ КАЧЕСТВ РЕЗИЛИЕНТНОСТИ У ПОДРОСТКОВ С ЗАДЕРЖКОЙ В ИНТЕЛЛЕКТУАЛЬНОМ РАЗВИТИИ И ПОДРОСТКОВ ТИПИЧНОГО РАЗВИТИЯ}

\begin{abstract}
Резюме Задержка в интеллектуальном развитии (ЗИР) представляет собой постоянное неблагоприятное условие, которое увеличивает вероятность отрицательных результатов в развитии. Целью данного исследования является определение различий между подростками с легкой ЗИР и подростками типичного развития (ТР) в индивидуальных качествах, которые способствуют успешной адаптачии. Исследование проведено на примере 92 подростков с легкой ЗИР и 772 подростков ТР, в возрасте от 13 до 19 лет. Для оценки резилиентности была использована Шкала резилиентности для детей и подростков. По сравнению с подростками ТP, подростков с легкой ЗИР характеризует более низкий уровень чувства контроля над собственной жизнью, чувства привязанности и более высокий уровень эмочиональной реактивности. В подгруппе подростков с легкой ЗИР значительных возрастных и гендерных различий в резилиентности не обнаружено. По сравнению $c$ подростками ТP, у подростков с легкой ЗИР обнаружен более низкий уровень устойчивости, что указывает на необходимость разработки программ, ориентированных на индивидуальные качества, которые связаны с положительными результатами в развитии.
\end{abstract}

Ключевые слова: подростки, задержка в интеллектуальном развитии, резилиентность 